\title{
Effect of ZSM-5 Acidity in Enhancement of Methanol-to-Olefins Process
}

\author{
Hambali H. U. ${ }^{1,3}$, Jalil A. A. ${ }^{1,2 *}$, Siang T. J. ${ }^{1}$, Abdulrasheed A. A. ${ }^{1}$, Fatah N. A. A. ${ }^{1}$, Hussain I. ${ }^{1,4}$, Azami M. S. ${ }^{1,4}$ \\ ${ }^{1}$ School of Chemical and Energy Engineering, Faculty of Engineering, Universiti Teknologi Malaysia, 81310 \\ Johor Bahru, Johor, Malaysia \\ ${ }^{2}$ Centre of Hydrogen Energy, Institute of Future Energy, Universiti Teknologi Malaysia, 81310 Johor Bahru, \\ Johor, Malaysia \\ ${ }^{3}$ Department of Chemical Engineering, University of Ilorin, PMB 1515, Ilorin, Nigeria \\ ${ }^{4}$ Department of Chemistry, Faculty of Science, Universiti Teknologi Malaysia, 81310 Johor Bahru, Johor, \\ Malaysia \\ *Corresponding author: aishahaj@utm.my
}

\begin{abstract}
Article History
Received: July 10, 2018 Received in revised form: February 13, 2019 Accepted: May 23, $2019 \quad$ Published Online: June 24,2019
\end{abstract}

\begin{abstract}
The skyrocketing demand for olefins especially propylene, have necessitated continuous efforts in finding alternate route for olefins production. Hence, methanol to olefins (MTO) was recognized as a feasible process since methanol could simply be mass produced from any gasifiable carbon-based feedstock, such as natural gas, coal, and biomass. Essentially, obtaining a more stable catalyst would improve economy of the MTO process. Acidity of catalyst has major influence in MTO, thus it is an indispensable parameter for conversion of methanol into value-added products. The present paper discusses the reactions involved in MTO process and the effect of acidity in enhancement of light olefin selectivity and catalytic stability. The paper also captured perspectives of crucial research and future direction for catalysts development and technologies that can potentiallly boost olefin production and make it competitive with the conventional olefin production processes.
\end{abstract}

Keywords: Methanol to olefins; propylene selectivity; ZSM-5; acidity; catalyst stability.

\subsection{INTRODUCTION}

Despite commercial production of olefins from crude oil resources via fluid and steam cracking processes, forecasted scarcity of petroleum resources and skyrocketing demand for olefins (especially propylene and ethylene) have necessitated continuous efforts in finding an alternate route for olefin production [1]. Hence, methanol to olefins (MTO) conversion is recognised as a feasible process since methanol could simply be mass produced from any gasifiable carbon-based feedstock, such as natural gas, coal, and biomass [2,3]. Acidity can be categorised into Bronsted acid sites (BAS) and Lewis acid sites (LAS). Generally, except for weak BAS, other types of acid sites are all from aluminium (Al) species, particularly strong acid sites that are produced by isomorphous substitution of $\mathrm{Al}$ for silicon $(\mathrm{Si})$ atom.

Essentially, the core interest in MTO process is to increase light olefin production due to forecasted scarcity of petroleum resources and skyrocketing demand for olefin selectivity. In turn, the ethylene to propylene ratio could be tuned by varying the acidity of zeolite and/or operating conditions among others. Solid acid catalysts such as zeolite and zeotype have been shown to play a crucial role in the conversion of methanol to olefins. ZSM-5 catalyst tends to have desirable physicochemical properties such as strong BAS, tunable acidity, and good thermal stability, which are all essential for the production of hydrocarbons $[4,5]$.

Intrinsically, BAS are the active sites for MTO reaction. Strong acidic sites favour the formation of undesired products (aromatics and alkanes) and lead to deactivation [5]. Therefore, the reduction of acid strength from strong to moderate/low BAS improves the formation of light olefins and reduces the rate of coke formation. In recent times, many researchers have devoted efforts to improve propylene selectivity and limit deactivation caused by coke deposition due to strong acidity of conventional ZSM-5 catalysts [6]. Nevertheless, some techniques have been adapted to adjust the acidity of ZSM-5 including post-synthesis treatment such as dealumination [7], altering $\mathrm{Si} / \mathrm{Al}$ ratio [8], the use of surfactants, and the addition of promoters 
[9].

Dealumination method entails the removal of aluminium atom from zeolite framework, thereby tuning the acidity. Feng et al. adapted dealumination process to fabricate ZSM-5 zeolite. The decreased concentration of surface aluminium atoms in modified ZSM-5 eventually improved propylene selectivity and catalyst lifetime in MTO reaction [10]. Therefore, through surface dealumination, the acidity decreases and limits pore blockage within ZSM-5 crystals. The present contribution studies the effect of acidity of ZSM-5 catalyst in the enhancement of MTO process. This present study covers published articles within the past five years, reporting strategies for enhancing propylene selectivity and catalytic stability in MTO reaction over ZSM5 catalyst.

\subsection{MTO REACTION NETWORK}

The technology of MTO is versatile, with the properties of catalyst and process conditions play a greater role on the nature of products formed. Numerous products are formed through different reactions such as methylation, cracking, oligomerisation, and cyclisation. Catalytic conversion of methanol progresses in two phases. Firstly, methanol is converted to an equilibrium mixture of dimethyl ether (DME), methanol, and water. In the second phase, the equilibrium mixture is converted to olefins and other products [11].

Figure 1 summarises the MTO reaction network routes. The reaction is initiated by the interaction of methanol with acid sites. The equilibrium mixture of methanol and DME undergoes methylation reaction, thereby producing olefin species. The produced olefins are converted to alkenes, alkanes, and aromatics through reactions such as methylation, cracking, and hydrogen transfer among others. MTO reaction proceeds via aromatics and alkenes routes over ZSM-5 zeolite, which are the widely accepted route for olefin generation from methanol.

The aromatic route generates higher polymethylbenzenes (higher polyMBs) molecules, which are regarded as the paramount hydrocarbon pool species (HCP). Eventually, higher fraction of aromatics products with traces of ethylene are produced through oligomerisation and elimination reactions. The alkene route on the other hand, is characterised by successive methylation and cracking reactions, with a large fraction of propylene and slight fractions of ethylene and alkanes are produced $[12,13]$.

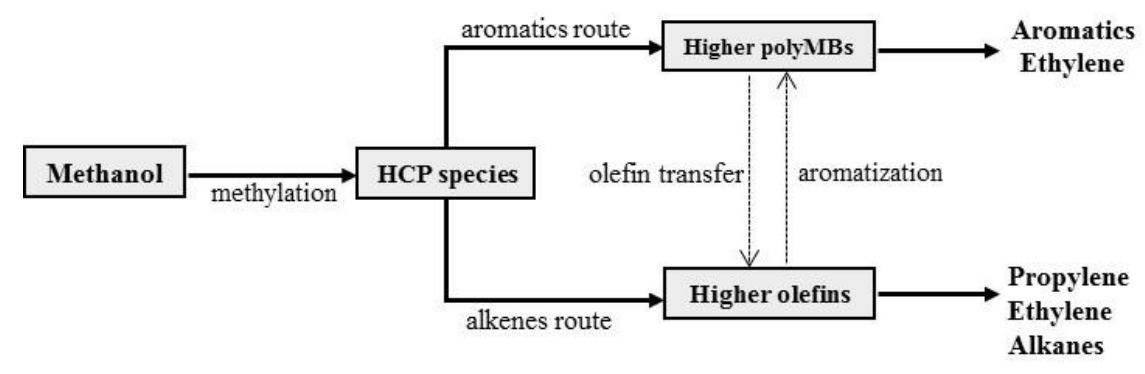

Figure 1. Methanol to olefins reaction network.

\subsection{RELATION OF ZSM-5 ACIDITY TO PERFORMANCE}

The acidity of ZSM-5 is an indispensable parameter for the generation of value- added products such as light olefins from methanol. ZSM-5 encompasses both BAS and LAS, which act as proton donors and electron-pair acceptors, respectively. BAS is generated by means of ion exchange with $\mathrm{NH} 4+$ and consequent thermal decomposition of ammonium ions to produce protons that counter balance the negative charge of the framework. Likewise, the chemical nature of LAS is comparable to that of BAS due to the extra framework of $\mathrm{Al}$ species and $\mathrm{Al}$ atoms located in the zeolite framework [14].

Generally, acid sites are located within channels or on the surface of zeolites and the sites promote acid-catalysed transformation, which MTO is inclusive. However, the strong BAS acceleration rate of coke precursor formation has the tendency to be adsorbed on the sites and lead to the blockage of pore openings and accelerate deactivation. Therefore, the acidity of catalyst must be adjusted [15]. Substantiated findings have shown that the reduction of ZSM-5 catalyst acidic strength improves stability and lighter olefin selectivity [16-20].

Furthermore, the existence of strong BAS propagates conspicuous generation of undesired products, such as aromatic species that are generated via hydrogen transfer reactions. As discussed in the previous section, the adjustment of ZSM-5 acidity is achieved by several techniques. Notably, dealumination method that is attainable by the removal of aluminium from the zeolite framework as first reported by Barrer et al. in 1964 [16]. Dealumination technique encompasses the application of chemical 
agents to remove aluminium from the framework, as well as hydrothermal dealumination [17]. Lago et al. used hydrothermal treatment at $540{ }^{\circ} \mathrm{C}$ in a gas stream by increasing water vapour partial pressure to achieve dealumination of ZSM-5 [18].

Basically, for hydrothermal treatment, the most adapted technique is the steaming process, which produces ZSM-5 catalysts with high stability [19]. The steaming process entails calcination of fresh catalyst in combination with acids over prolonged synthesis duration (more than $10 \mathrm{~h}$ ) and high temperature $\left(400-800{ }^{\circ} \mathrm{C}\right)[20]$.

Recently, comprehensive investigations have been conducted on catalytic performance of modified ZSM-5 catalysts in MTO process. For example, Zhang et al. adopted steaming technique at optimum conditions $\left(500{ }^{\circ} \mathrm{C}\right.$ and $\left.12 \mathrm{~h}\right)$ to synthesise modified ZSM-5 catalyst with improved activity in MTO reaction [21]. Also, Leilei et al. synthesised dealuminated ZSM-5 catalysts with the aid of ammonium surfactants. The result shows that deactivation due to coking effect largely depends on BAS concentration. ZSM-5 catalyst with moderate acidity (BAS of 0.30 and LAS $0.20 \mathrm{mmol}$ g-1) gave the highest propylene selectivity (37\%) and less coke content [22]. An outstanding report from Nordvang et al. further revealed that ZSM-5 acidity has a great impact on stability. It was shown that materials with high coking tendency such as polyaromatic species were swiftly generated on the external catalyst surface, which limited diffusion of reactants and products within the catalyst, and consequently led to deactivation [23].

Astonishingly, Pit et al. passivated ZSM-5 catalysts by chemical dealumination technique using tetraethyl-orthosilicate. The passivation was repeated for a second and third time to guarantee complete surface coverage. BAS and LAS were determined by pyridine adsorption. Table 1 displays the acidic properties and catalytic performance of the catalysts in MTO process. ZSM$5 \mathrm{NF}$ is the synthesised nano-zeolite, whereas ZSM-5P1, ZSM-5P2, and ZSM-5P3 denote once to thrice passivated samples, respectively. The once-passivated catalyst (ZSM-5P1) had moderate acidity in relative to other catalysts and gave the highest propylene selectivity of $34 \%$ compared to others [24]. In addition, Rey et al. reported that a higher amount of acid sites on ZSM-5 accounts for lower catalytic stability because aromatic species have the tendency to arouse coke species [25]. More recently, Rui et al. modified ZSM-5 with surface dealumination. Improved light olefin selectivity (63.54\%), propylene selectivity (40.79\%), and catalyst lifetime (24 h) were observed [26].

Table 1. Acidic properties and catalytic performance of the catalysts.

\begin{tabular}{|c|c|c|c|c|c|c|c|c|}
\hline \multirow{2}{*}{ Zeolite } & \multirow{2}{*}{$\begin{array}{c}\text { BAS } \\
(\mu \mathrm{mol} g-1)\end{array}$} & \multirow{2}{*}{$\begin{array}{c}\text { LAS } \\
(\mu \mathrm{mol} g-1)\end{array}$} & \multirow{2}{*}{$\begin{array}{c}\text { Conversion } \\
(\%)\end{array}$} & \multicolumn{5}{|c|}{ Selectivity (\%) } \\
\hline & & & & $\mathrm{C}_{2}=$ & $\mathrm{C}_{3}=$ & $\mathrm{C}_{4}=$ & $\mathrm{C}_{5}=$ & $\mathrm{C}_{6+}$ \\
\hline $\mathrm{ZSM}-5_{\mathrm{NF}}$ & 137 & 36 & 98 & 14 & 29 & 11 & 10 & 16 \\
\hline $\mathrm{ZSM}-5_{\mathrm{P} 1}$ & 126 & 38 & 97 & 26 & 34 & 2 & 3 & 19 \\
\hline $\mathrm{ZSM}-5_{\mathrm{P} 2}$ & 132 & 40 & 97 & 27 & 27 & 5 & 6 & 21 \\
\hline $\mathrm{ZSM}-5_{\mathrm{P} 3}$ & 89 & 34 & 90 & 28 & 33 & 5 & 6 & 14 \\
\hline
\end{tabular}

\subsection{CONCLUSION AND PROSPECTS}

An efficient tool to optimise MTO process is by tuning the acidity of conventional ZSM-5 catalyst. As discussed, strong acid sites increase the rate of coke formation through side reactions and reduce the generation of light olefin species. Thus, ZSM-5 modification process shows a decrease in acid sites strength, which slows down channel blockage, thereby improving catalytic performance. Furthermore, modified ZSM-5 with low acidity plays a major role in the network of MTO process by inhibiting undesired product formation via aromatics routes and shifting the reaction to alkene route, which favours light olefin production. Therefore, the appropriate acid property of ZSM-5 catalyst for enhanced MTO process is a combination of weak and/or moderate acid sites.

MTO is a fascinating and significant reaction for both academic research and industrial applications. Incessant efforts have been devoted to improving light olefin production, which include modification of conventional catalysts, use of other reactants, and co-feeding methanol with water. The conventional cracking processes are still the cheapest methods to produce propylene and the processes account for around $90 \%$ of the global propylene supply. However, they do not fully content the rising demand for propylene in the petrochemical market. As a result, post-treatment techniques such as elements and composite incorporation should be considered. Furthermore, propylene producing technologies such as ethene to propene, olefin cracking, and propane dehydrogenation should be adopted. These technologies have the potential to produce a significant amount of propylene and are predicted to contribute about $30 \%$ of the global propene production [27]. Another viable option is co-feeding methanol with water. The existence of water in the feed reduces the rate of coke formation by competing for surface sites with coke precursors. Not long ago, an investigation by Parisa et al. showed that using an equivalent quantity of methanol and water in the feed boosted the selectivity of propylene [28].

Recently, other types of modified zeolite materials are being explored in MTO process. Pablo et al. reported the production of 
substantial heavier olefin fraction in MTO process over desilicated ZSM-22 catalyst. However, low catalyst stability was observed, which would require frequent regeneration in practical industrial application [29]. Also, Xiaojing et al. explored modified silicalite-2 zeolite in MTO process. Nearly $100 \%$ methanol conversion and $15 \%$ propene yield were achieved, and significant catalytic stability and increased tolerance for coke deposition were recorded [30]. Sung et al. reported a similar trend. Amazingly, the catalytic performance of MTO over ferrierite zeolite was improved by CeO2 coating. A product distribution of almost $90 \%$ higher olefins and free aromatics was obtained [31]. In the near future, fundamental investigations on hierarchical, nano-, and meso-structured materials would further be established, and in-depth understanding of MTO mechanisms would be revealed, whereas the projection for further MTO catalyst innovation is expected to be on the rise.

\section{Acknowledgements}

This work was supported by the Ministry of Higher Education (MOHE) Malaysia through Fundamental Research Grant No. FRGS/1/2017/STG07/UTM/01/1 (Grant No. 4F969).

\section{References}

[1] Sun, C., J. M. Du, J. Liu, Y. S. Yang, N. Ren, W. Shen, H. L. Xu, and Y. Tang. 2010. A Facile Route To Synthesize Endurable Mesopore Containing ZSM-5 Catalyst For Methanol To Propylene Reaction. Chemical Communications. 46: 2671-2673.

[2] Hickman, D. A. and L. D. Schmidt. 1993. Production of Syngas by Direct Catalytic Oxidation of Methane. Science. 259: $343-346$.

[3] Wen, W. Y. 1980. Mechanisms of Alkali Metal Catalysis in the Gasification of Coal, Char, or Graphite. Catalysis Reviews Science and Engineering. 22:1-28.

[4 Qian, Q., J. Ruiz-Martinez, M. Mokhtar, A. M. Asiri, S. A. Al- Thabaiti, S. N. Basahel, and B. M. Weckhuysen. 2014. Single-Catalyst Particle Spectroscopy Of Alcohol-To-Olefins Conversions: Comparison between SAPO-34 and SSZ-13. Catalysis Today. 226 : 14-24.

[5] Hu, H., J. Lyu, J. Rui, J. Cen, Q. Zhang, Q. Wang, W. Han, and X. Li. 2016. The Effect Of Si/Al Ratio On The Catalytic Performance Of Hierarchical Porous ZSM-5 For Catalyzing Benzene Alkylation With Methanol. Catalysis Science \& Technology. 6: 2647-2652.

[6] Muller, S., Y. Liu, M. Vishnuvarthan, X. Sun, A.C. Van-Veen, G.L. Haller, M. Sanchez-Sanchez, and J.A. Lercher. 2015. Coke Formation And Deactivation Pathways On H-ZSM-5 In The Conversion Of Methanol To Olefins. Journal of Catalysis. 325: 48-59.

[7] Ong, L. H., M. Domok, R. Olindo, A. C. van Veen, and J. A. Lercher. Dealumination of HZSM-5 Via Steam-Treatment. Microporous Mesoporous Mater. 164: 9-20.

[8] Wei, R. C., C. Y. Li, C. H. Yang, and H. H. Shan. 2011. Effects of Ammonium Exchange And Si/Al Ratio On The Conversion Of Methanol To Propylene Over A Novel And Large Partical Size ZSM-5. Journal of Natural Gas Chemistry. 20: 261-265.

[9] Hadi, N., A. Niaei, S. R. Nabavi, M. Navaei Shirazi, and R. Alizadeh. 2015. Effect of Second Metal On The Selectivity Of Mn/H-ZSM-5 Catalyst In Methanol To Propylene Process. Journal of Industrial and Engineering Chemistry. 29: 52-62.

[10] Feng, R., X. Yana, X. Hua, Z. Yanb, J. Lina, Z. Lia, K. Houa, and M. J. Rood. 2018. Surface Dealumination Of Micro-Sized ZSM-5 For Improving Propylene Selectivity And Catalyst Lifetime In Methanol To Propylene (MTP) reaction. Catalysis Communications. 109: 1-5.

[11] Tarach, K.A., J. Martinez-Triguero, F. Rey, and K. Gora-Marek. 2016. Hydrothermal Stability And Catalytic Performance Of Desilicated Highly Siliceous Zeolites ZSM-5. Journal of Catalysis. 339: 256-269.

[12] Dessau, R.M., and R.B. Lapierre. 1982. On the Mechanism Of Methanol Conversion To Hydrocarbons over HZSM-5. Journal of Catalysis. 78: 136141.

[13] Wang, S., Y. Y. Chen, Z. H. Wei, Z. F. Qin, H. Ma, M. Dong, J. F. Li, W. B. Fan, and J. G. Wang. 2015. The Journal of Physical Chemistry C. 119: 28482-28498.

[14] Zhu, Q., N. K. Junko, and T. Tatsumi. 2018. Co-Reaction Of Methanol And Ethylene Over MFI And CHA Zeolitic Catalysts. Microporous and Mesoporous Materials. 255: 174-184.

[15] Yang, Y. S., C. Sun, J. M. Du, Y. H. Yue, W. M. Hua, C. L. Zhang, W. Shen, and H. L. Xu. 2012. The Synthesis Of Endurable B-Al-ZSM-5 Catalysts With Tunable Acidity For Methanol To Propylene Reaction. Catalysis Communications. 24: 44-47.

[16] Barrer, R. M., and M. B. Makki. 1964. Molecular Sieve Sorbents From Clinoptilolite. Canadian Journal of Chemistry. $42: 1481-1487$.

[17] Qin, Z. X., J. P. Gilson, and V. Valtchev. 2015. Mesoporous Zeolites By Fluoride Etching. Current Opinion in Chemical Engineering. 8: 1-6. 
[18] Lago, R. M., W. O. Haag, R. J. Mikovsky, D. H. Olson, S. D. Hellring, K. D. Schmitt, and G. T. Kerr.1986. The Nature of the Catalytic Sites in HZSM5- Activity Enhancement. Studies in Surface Science and Catalysis. 28: 677-684.

[19] Zhang, Y. W., Y. M. Zhou, K. Z. Yang, Y. Li, Y. Wang, Y. Xu, and P. C. Wu. 2006. Effect of Hydrothermal Treatment On Catalytic Properties Of Ptsnna/ZSM-5 Catalyst For Propane Dehydrogenation. Microporous Mesoporous Mater. 96: 245-254.

[20] Fan, Y., X. J. Bao, X. Y. Lin, G. Shi, and H. Y. Liu. 2006. Acidity Adjustment of HZSM-5 Zeolites by Dealumination and Realumination with Steaming and Citric Acid Treatments. The Journal of Physical Chemistry B. 110: 15411-15416.

[21] Zhang, S. L., Y. J. Gong, Y. S. Liu, T. Dou, J. Xu, F. Deng. 2015. Hydrothermal Treatment On ZSM-5 Extrudates Catalyst For Methanol To Propylene Reaction: Finely Tuning The Acidic Property. Fuel Processing Technology. 129: 130-138.

[22] Wu, L., Pieter C.M.M. Magusin, V. Degirmenci, M. Li, M.T. Sami, X. Zhu, B. Mezari, and E. J.M. Hensen. 2014. Acidic Properties Of Nanolayered ZSM-5 Zeolites. Microporous and Mesoporous Materials. 189: 144-157.

[23] Nordvang, E. C., E. Borodina, J. Ruiz-Martinez, R. Fehrmann, and B. M. Weckhuysen. 2015. Effects of Coke Deposits on the Catalytic Performance of Large Zeolite H-ZSM-5 Crystals during Alcohol-to-Hydrocarbon Reactions as Investigated by a Combination of Optical Spectroscopy and Microscopy. Chemistry: A European Journal. 21: 17324-17335.

[24] Losch, P., M. Boltza, C. Bernardona, B. Louisa, P. Ana, and V. Valtchev. 2016. Applied Catalysis A. $509: 30-37$.

[25] Rey, J., P. Raybaud, and C. Chizallet. 2017. Ab Initio Simulation of the Acid Sites at the External Surface of Zeolite Beta. ChemCatChem Journal. 9: 2176-2185.

[26] Feng, R., X. Yana, X. Hua, Z. Yan, J. Lina, Z. Lia, and K. Hou. 2018. Surface Dealumination Of Micro-Sized ZSM-5 For Improving Propylene Selectivity And Catalyst Lifetime In Methanol To Propylene (MTP) reaction. Catalysis Communications. 109: 1-5.

[27] Blay, V., E. Epelde, R. Miravalles, and L. Alvarado Perea. 2018. Converting Olefins To Propene: Ethene To Propene And Olefin Cracking. Catalysis Reviews. 60: 278-335.

[28] Sadeghpour, P., and M. Haghighi. 2018. High-Temperature And Short-Time Hydrothermal Fabrication Of Nanostructured ZSM-5 Catalyst With Suitable Pore Geometry And Strong Intrinsic Acidity Used In Methanol To Light Olefins Conversion. Advanced Powder Technology. 29: $1175-1188$.

[29] Campo, P. D., U. Olsbye, K. P. Lillerud, S. Svelle, and P. Beato. 2018. Impact of Post-Synthetic Treatments On Unidirectional H-ZSM-22 Zeolite Catalyst: Towards Improved Clean MTG Catalytic Process. Catalysis Today. 299: 135-145.

[30] Meng, X., M. Zhang, C. Chen, C. Li, W. Xiong, and M. Li. 2018. Insights Into The Role Of Silanols In Methanol To Propene Reaction Over Silicalite2 Zeolite Through Post-Treatments. Applied Catalysis A. 558: 122-130.

[31] Park, S. J., H. Jang, K. Y. Lee, and S. J. Cho. 2018. Improved Methanol-To-Olefin Reaction Selectivity And Catalyst Life By Ceo 2 Coating Of Ferrierite Zeolite. Microporous and Mesoporous Materials. 256: 155-164. 